\title{
Detection of Novel Gene Variants Associated with Congenital Hypothyroidism in a Finnish Patient Cohort
}

\author{
Christoffer Löf, Konrad Patyra,, Teemu Kuulasmaa,2 Jagadish Vangipurapu,2 Henriette Undeutsch, \\ Holger Jaeschke,, Tuulia Pajunen,, Andreina Kero, Heiko Krude, Heike Biebermann, \\ Gunnar Kleinau, Peter Kühnen,3 Krista Rantakari, Päivi Miettinen, Turkka Kirjavainen, \\ Juha-Pekka Pursiheimo, Taina Mustila, Jarmo Jääskeläinen, ${ }^{6}$ Marja Ojaniemi, Jorma Toppari, ${ }^{1,8}$ \\ Jaakko Ignatius, Markku Laakso, and Jukka Kero ${ }^{1,8}$
}

Background: Congenital hypothyroidism $(\mathrm{CH})$ is defined as the lack of thyroid hormones at birth. Mutations in at least 15 different genes have been associated with this disease. While up to $20 \%$ of $\mathrm{CH}$ cases are hereditary, the majority of cases are sporadic with unknown etiology. Apart from a monogenic pattern of inheritance, multigenic mechanisms have been suggested to play a role in $\mathrm{CH}$. The genetics of $\mathrm{CH}$ has not been studied in Finland so far. Therefore, multigenic sequencing of $\mathrm{CH}$ candidate genes was performed in a Finnish patient cohort with both familial and sporadic $\mathrm{CH}$.

Methods: A targeted next-generation sequencing (NGS) panel, covering all exons of the major $\mathrm{CH}$ genes, was applied for 15 patients with sporadic and 11 index cases with familial $\mathrm{CH}$.

Results: Among the familial cases, six pathogenic mutations were found in the TPO, PAX8, and TSHR genes. Furthermore, pathogenic $N K X 2.1$ and $T G$ mutations were identified from sporadic cases, together with likely pathogenic variants in the TG, NKX2.5, SLC26A4, and DUOX2 genes. All identified novel pathogenic mutations were confirmed by Sanger-sequencing and characterized in silico and/or in vitro.

Conclusion: In summary, the $\mathrm{CH}$ panel provides an efficient, cost-effective, and multigenic screening tool for both known and novel $\mathrm{CH}$ gene mutations. Hence, it may be a useful method to identify accurately the genetic etiology for dyshormogenic, familial, or syndromic forms of $\mathrm{CH}$.

\section{Introduction}

$\mathbf{P}$ RIMARY CONGENITAL hYPOTHYROIDISM $(\mathrm{CH})$ is a relatively common endocrine disease affecting 1 in 20004000 newborns worldwide (1-3). It is defined as the lack of thyroid hormones at birth. If not identified and treated promptly, it can lead to severe developmental delay and mental retardation (4). In addition, patients with syndromic $\mathrm{CH}$ often have other congenital malformations such as lung, kidney, or heart defects (5). Therefore, in many countries, newborn children are screened for $\mathrm{CH}$ by measuring serum thyrotropin (TSH) and/or thyroxine (T4).

The majority $(80 \%)$ of primary $\mathrm{CH}$ is a consequence of thyroid dysgenesis (TD) - developmental abnormalities of the thyroid gland ranging from the lack of thyroid gland (athyreosis) to a hypoplastic or ectopic gland. The remaining fraction (10-20\%) of $\mathrm{CH}$ has been associated with hereditary defects in genes involved in thyroid hormone synthesis, termed as thyroid dyshormogenesis (DH). Although TD is mainly considered as a sporadic disease, a genetic component has been

\footnotetext{
${ }^{1}$ Department of Physiology; ${ }^{5}$ Turku Clinical Sequencing Laboratory, Institute of Biomedicine, University of Turku, Turku, Finland.

${ }^{2}$ Faculty of Health Sciences, Institute of Clinical Medicine, Internal Medicine, University of Eastern Finland, Kuopio, Finland.

${ }^{3}$ Institute of Experimental Pediatric Endocrinology, Charité Universitätsmedizin Berlin, Berlin, Germany.

${ }^{4}$ Hospital for Children and Adolescents, Hospital District of Helsinki and Uusimaa, Helsinki, Finland.

${ }^{6}$ Department of Pediatrics, Seinäjoki Central Hospital, Seinäjoki, Finland.

${ }^{7}$ Department of Children and Adolescents, Oulu University Hospital, Oulu, Finland.

Departments of ${ }^{8}$ Pediatrics and ${ }^{9}$ Clinical Genetics, Turku University Hospital, Turku, Finland.
}

(c) Christoffer Löf et al. 2016; Published by Mary Ann Liebert, Inc. This Open Access article is distributed under the terms of the Creative Commons Attribution Noncommercial License (http://creativecommons.org/licenses/by-nc/4.0/) which permits any noncommercial use, distribution, and reproduction in any medium, provided the original author(s) and the source are credited. 
proposed to be involved. In population studies, the prevalence of TD, as well as other thyroid abnormalities, has been significantly higher in first-degree relatives $(6,7)$. Apart from a monogenic pattern of inheritance, multigenic and epigenetic mechanisms have been suggested to play a role in TD. To date, mutations in more than 15 genes have been reported to cause primary $\mathrm{CH}$ (8). All mutations affect either transcription factors that regulate thyroid-specific genes and thyroid development or genes responsible for thyroid hormone production. In addition to primary $\mathrm{CH}$, mutations in genes regulating the hypothalamus-pituitary-thyroid axis can also lead to rare central hypothyroidism (1:50,000 newborns) (9).

This study established a targeted next-generation sequencing (NGS) panel for multigenic screening to identify the underlying genetic etiology of $\mathrm{CH}$ in hereditary and sporadic $\mathrm{CH}$ patients.

\section{Materials and Methods}

Study subjects, diagnostic criteria for $\mathrm{CH}$, and laboratory measurements

Pediatric endocrinologists from different pediatric departments in Finland (Helsinki, Kuopio, Oulu, Turku, Vaasa, Seinäjoki) recruited patients with $\mathrm{CH}$. The patients and their parents were asked to sign a written informed consent to take part in the study. The Ethics Committee of the Hospital District of Southwest Finland approved the study (108/180/2010).

The diagnosis of permanent $\mathrm{CH}$ was based on TSH and T4 screening test at birth and confirmation test results at two to three years of age after cessation of T4 treatment temporarily. $\mathrm{CH}$ screening in Finland is based on the measurement of TSH levels from umbilical serum at birth. Where an abnormal (TSH $>40 \mathrm{mIU} / \mathrm{L}$ ) result is found, serum T4 is determined from the same sample, and a confirmation sample (for both TSH and T4) is taken when the newborn is 72 hours old. This screening leads to an early start to therapy and has a low rate of false-positive cases (10). Iodine uptake or iodine accumulation tests were not performed routinely. Serum thyroglobulin (TG) levels at the time of recruitment were measured by commercial ELISA (Novatec, Baltimore, MD). DNA from whole-blood samples was isolated with a kit (Qiagen, Valencia, CA). A total of 34 DNA samples were sequenced using the targeted NGS panel containing the genes listed in Table 1 . The cohort included both cases with thyroid dysgenesis and dyshormogenesis. The other 17 DNA samples were obtained from sporadic cases, including 15 cases with permanent $\mathrm{CH}$ and two with hyperthyrotropinemia. Analyses included four $\mathrm{CH}$ patients with five known mutations in different genes responsible for $\mathrm{CH}$ (Supplementary Table S1; Supplementary Data are available online at www.liebertpub.com/thy). Eleven $\mathrm{CH}$ samples were index cases from unrelated families with at least two affected family members. The summary of the clinical data is described in Figure 1 and in further detail in the supplementary section (Supplementary Materials and Methods).

\section{Design and general performance of the sequencing panel for $\mathrm{CH}$ genes}

The NGS panel consisted of $13 \mathrm{CH}$ genes (Table 1). The aim was to cover all exons and exon-intron boundaries in genes known to cause $\mathrm{CH}$ using the Haloplex targeting system (Agilent, Santa Clara, CA). The custom primers were
TABle 1. List and the Coverage OF THE GENES INCLUDED IN THE NGS PANEL USED FOR THE GENETIC CH SCREENING

\begin{tabular}{|c|c|c|c|c|}
\hline $\begin{array}{l}\text { Target } \\
\text { ID }\end{array}$ & Regions & Coverage & $\begin{array}{c}\text { High } \\
\text { coverage } \\
(\geq 90 \%)\end{array}$ & $\begin{array}{c}\text { Low } \\
\text { coverage } \\
(<90 \%)\end{array}$ \\
\hline$D U O X 1^{\mathrm{a}}$ & 33 & $95.83 \%$ & 31 & 2 \\
\hline$D U O X 2$ & 32 & $95.82 \%$ & 31 & 2 \\
\hline$I Y D$ & 8 & $100.00 \%$ & 8 & 0 \\
\hline$N K X 2-5$ & 4 & $100.00 \%$ & 4 & 0 \\
\hline$P A X 8$ & 11 & $100.00 \%$ & 11 & 0 \\
\hline$S L C 26 A 4$ & 21 & $99.71 \%$ & 21 & 0 \\
\hline SLC $5 A 5$ & 15 & $99.85 \%$ & 15 & 0 \\
\hline$T G$ & 50 & $100.00 \%$ & 50 & 0 \\
\hline$T P O$ & 18 & $100.00 \%$ & 18 & 0 \\
\hline$T R H^{\mathrm{a}}$ & 2 & $100.00 \%$ & 2 & 0 \\
\hline$T R H R^{\mathrm{b}}$ & 2 & $100.00 \%$ & 2 & 0 \\
\hline$T S H B^{\mathrm{b}}$ & 2 & $100.00 \%$ & 2 & 0 \\
\hline$T S H R$ & 11 & $100.00 \%$ & 11 & 0 \\
\hline
\end{tabular}

Three other known $\mathrm{CH}$ genes (DUOXA2, FOXE1, and IGSF1) were not included in the screening panel. Furthermore, the NKX2-1 exons were previously sequenced.

${ }^{a}$ Not previously linked to primary $\mathrm{CH}$.

${ }^{\mathrm{b}}$ Usually associated with central $\mathrm{CH}$.

NGS, next-generation sequencing; $\mathrm{CH}$, congenital hypothyroidism.

designed using the Sure Design tool (Agilent Technologies, Santa Clara, CA) to generate 2219 amplicons with $250 \mathrm{bp}$ length covering $>99 \%$ of the target gene exon areas comprising 213 regions. The total amount of target bases was $38.157 \mathrm{kbp}$. Samples were sequenced using Illumina's MiSeq instrument (Illumina, San Diego, CA). After sequencing, 97\% (208/213) of the targeted regions showed excessive coverage $(>500)$, and three target region had coverage between 50 and 500. There were gaps in two targeted regions in the DUOX2 (1/32 DUOX2 targets) and DUOX1 (1/33 targets) gene regions. All five mutations in the controls were identified with high read depth $(>700)$ and expected allelic frequencies (Supplementary Table S1). Among all filtered variants confirmed by Sanger sequencing $(n=30)$, no falsepositive variants were observed.

\section{Data analysis and filtering}

An in-house developed analysis pipeline was used for the evaluation of raw fastq files generated by the MiSeq-sequencer. Cutadapt (https://code.google.com/p/cutadapt/) software served for adapter removal and read trimming. Reads shorter than $20 \mathrm{bp}$ were abandoned. The remaining reads were mapped to the human reference genome hg19 using a BWA-MEM algorithm (http://bio-bwa.sourceforge.net/). Variant calling (SNVs and indels) was performed using four different variant caller tools: GATK HaplotypeCaller (www.broadinstitute.org/gatk/), SAMTools mpileup (http://samtools.sourceforge.net/), Atlas2 (http://sourceforge.net/projects/atlas2/), and Platypus (www .well.ox.ac.uk/platypus). All called variants were annotated using SnpEff (http://snpeff.sourceforge.net/), ANNOVAR (http:// annovar.openbioinformatics.org/), and multiple different public databases (e.g., ExAC, 1000 Genomes, dbSNP, and ClinVar). Variants met the following inclusion criteria for the downstream analysis: located within the exon or splicing regions, a high or moderate effect on gene function, and an unknown or variant allele frequency $<1 \%$ in the 1000 genomes variant database. 


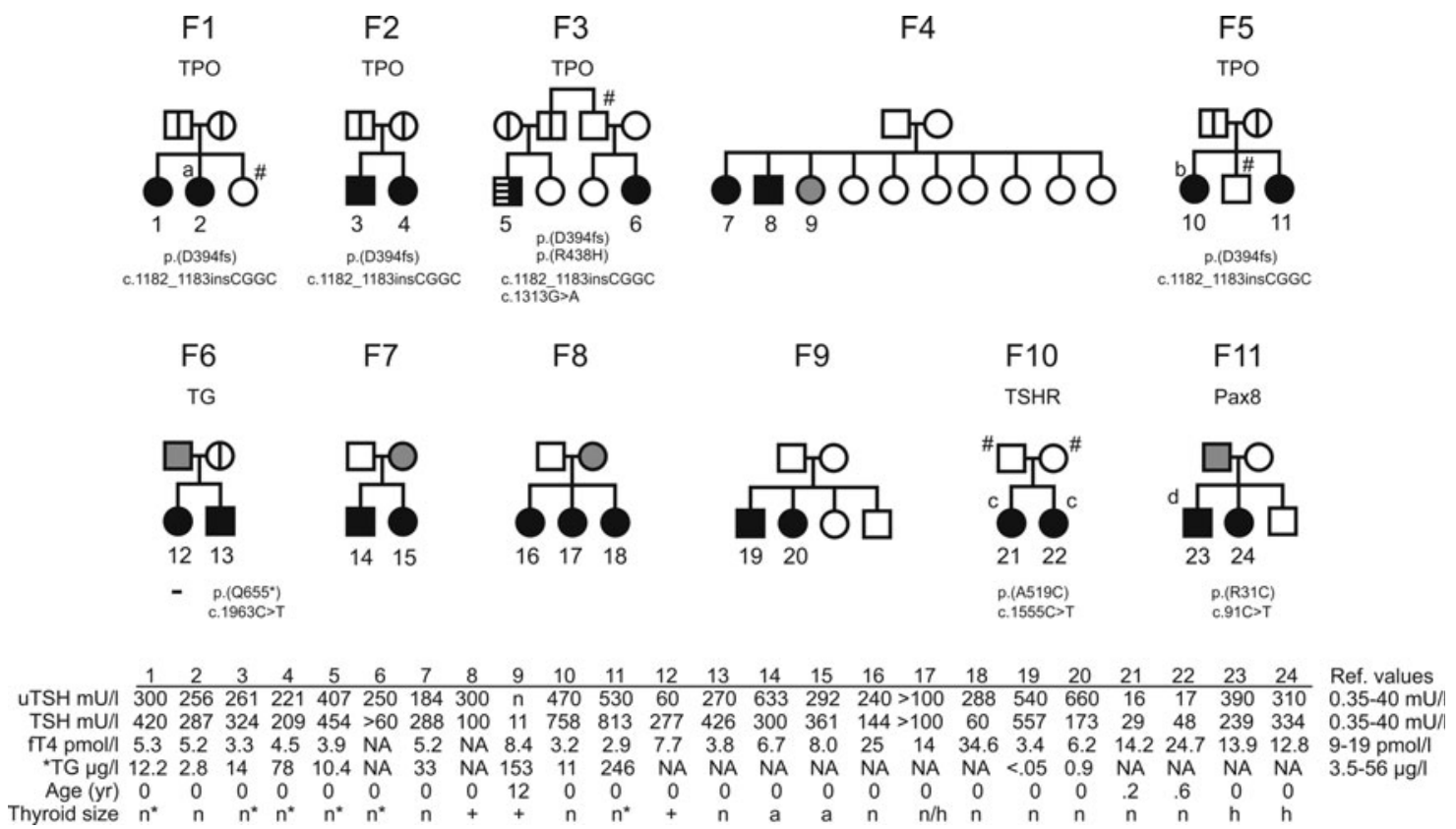

FIG. 1. Modified pedigrees and identified mutations of the familial congenital hypothyroidism $(\mathrm{CH})$ cases with genetic and clinical data. The results of the thyroid function tests and thyroid size are aligned below. The reference values of umbilical blood thyrotropin (uTSH), and thyrotropin (TSH) and free thyroxine (fT4) serum hormone levels at three days of age or the time of diagnosis are included. Black, affected patients with $\mathrm{CH}$; symbols with midline, asymptomatic heterozygous carriers; gray, adult onset hypothyroidism; white, no thyroid disease. Lined box (case 5) indicates the TPO R438H mutation. Serum thyroglobulin (TG) levels were measured at the time of enrollment into the study. The age (years) at time of diagnosis $(0=$ at birth $)$ is shown. Thyroid size evaluated by thyroid ultrasound if data available (n, normal thyroid size and location; +, goiter; a, athyreosis/no thyroid gland not detected; h, hypoplastic or small thyroid; $\mathrm{n}^{*}$, no clinical signs of goiter during follow-up; \#, no DNA available). The detailed clinical information of the families is described in the Supplementary Materials and Methods. NA, data not available. ${ }^{\mathrm{a}}$ Patient had mild hypotonia, delay of development (speech and motor development) and abnormal hearing response, ${ }^{b}$ abnormal hearing, ${ }^{c}$ born in week $29+3$, or ${ }^{\mathrm{d}}$ renal agenesis.

The alignments at variant positions were visually inspected using the Integrative Genomics Viewer (www.broadinstitute .org/igv/; Supplementary Fig. S1). Variants that met these conditions and passed visual inspection were annotated using Condel (http://bg.upf.edu/fannsdb/). After the filtration procedure, the putative pathogenic variants were confirmed by Sanger sequencing using a commercial service (GATC Biotech, Germany). Furthermore, Sanger sequencing was used for the segregation analysis of the family members. Primers (sequences available upon request) were designed for all variants listed in Tables 2 and 4, used for genomic polymerase chain reaction to amplify DNA flanking the variant. All three exons of $N K X 2.1$ were sequenced as previously described (11). Furthermore, array-based comparative genomic hybridization (CGH) and multiplex ligation-dependent gene (MLPA) analysis for NKX2.1 gene deletion and duplication was performed at CeGAT laboratories (GeCAT GmbH, Tübingen, Germany) for a sporadic case with nearly lethal respiratory failure at birth.

\section{Protein modeling and in vitro experiments}

The impact of TPO and $P A X 8$ mutations on protein function was investigated using protein modeling, as described in

Table 2. Pathogenic Mutations Identified from Familial CH Cases

\begin{tabular}{|c|c|c|c|c|c|c|c|c|}
\hline Fig. 1 no. & Gene & GeneBank & Base change & $\begin{array}{l}\text { Protein } \\
\text { change }\end{array}$ & ExAC MAF & $\begin{array}{l}\text { Mono-/ } \\
\text { biallelic }\end{array}$ & $\begin{array}{l}\text { Read } \\
\text { depth }\end{array}$ & Classification \\
\hline 2 & $T P O$ & 000547.5 & c.1182_1183insCGGC & D394fs & - & Biallelic & 11 & A \\
\hline 3 & $T P O$ & 000547.5 & c.1182_1183insCGGC & D394fs & - & Biallelic & 3 & A \\
\hline 5 & $T P O$ & 000547.5 & c.1182_1183insCGGC & D394fs & - & Monoallelic & 4 & A \\
\hline 5 & TPO & 000547.5 & c.1313G $>$ A & R438H & - & Monoallelic & 997 & B \\
\hline 10 & $T P O$ & 000547.5 & c.1182_1183insCGGC & D394fs & - & Biallelic & 8 & A \\
\hline 13 & $T G$ & 003235.4 & c.1963C $>\mathrm{T}$ & Q655* & 0.0001 & Monoallelic & 887 & B \\
\hline 21 & TSHR & 000369.2 & c. $1555 \mathrm{C}>\mathrm{T}$ & R519C & 0.00004 & Monoallelic & 997 & A \\
\hline 23 & PAX8 & 003466.3 & c. $91 \mathrm{C}>\mathrm{T}$ & R31C & - & Monoallelic & 992 & A \\
\hline
\end{tabular}

Novel $T G$ and $T P O$ mutations shown in bold.

A, pathogenic mutation (based on segregation, literature, and in vitro experiments); B, likely pathogenic mutation (predicted pathogenicity in silico and/or modeling analysis); ExAC MAF, allelic frequency in The Exome Aggregation Consortium database. 
more detail in the Supplementary Materials and Methods. A luciferase reporter assay was performed to evaluate the pathogenicity of the mutations in $N K X 2.1$ and $P A X 8$, as described in the Supplementary Materials and Methods. The wild-type pcDNA3.1-NKX2.1 plasmid containing the short version of NKX2.1 was obtained from Addgene (plasmid 49989; Addgene, Cambridge, MA) (12). The wild-type pcDNA3-PAX8 plasmid was a kind gift from Dr. Knut Krohn (University of Leipzig, Leipzig, Germany).

\section{Results}

\section{Results from the familial cases}

Among the 11 index cases with familial $\mathrm{CH}$, the following thyroid or associated phenotypes were found: goiter, athyreosis, thyroid gland hypoplasia, kidney agenesis, and, in one family, the cases were twins born prematurely at gestational week $29+3$ (Fig. 1). Other families showed no obvious phenotypic signs or syndromes. Among 11 families, five were from the same district in Finland. In four of those families, a frameshift (fs) mutation (c.1182_1183ins CGGC) in the TPO gene in exon 8 was identified. This fs mutation altered the amino acid sequence of TPO after amino acid 394, and introduced a premature stop codon in exon 9. This change led to a large truncation of TPO and its peroxidase domain with no expected activity (Fig. 2). In three out of four families, this TPO mutation was homozygous in affected children. The thyroid ultrasound was normal, and no clinical goiter was observed in the affected cases during the clinical follow-up. Parents were heterozygous carriers, and all had a normal thyroid size and function. In family F3 (Fig. 1, F3), two cousins (\#5 and \#6) with $\mathrm{CH}$ had a heterozygous TPOfs mutation. Besides this mutation, one of them (\#5) also had a rare novel heterozygous c.1313G $>$ A, p.R438H mutation, which is absent in databanks and located in a well-established functional TPO domain. Based on the structural protein modeling, the histidine mutant at position 438 impairs the important intramolecular interaction. This led to the modification of the structural adjustment inside the domain, which is essential for regular enzymatic function of TPO (Fig. 2). The heterozygous TPOfs mutation was present in the mother and the $R 438 H$ mutation in the father with normal thyroid function tests (TFTs). Thus, these compound heterozygous mutations of TPO most likely explain the development of $\mathrm{CH}$ in this patient. However, only the TPOfs mutation could be identified, not another $T P O$ variant from his cousin who also suffered from $\mathrm{CH}$.

In family F10, a heterozygous mutation in the TSHR $1555 \mathrm{C}>\mathrm{T}$, p.R519C was found in identical twins, born prematurely at week 29+3 (Fig. 1 and Supplementary Materials and Methods). In the initial $\mathrm{CH}$ screening, umbilical TSH serum levels were under the cutoff level (16 and $17 \mathrm{mIU} / \mathrm{L}$; reference value $>20 \mathrm{mIU} / \mathrm{L}$ ), but serum TSH levels were elevated during follow-up. Serum TSH concentrations were markedly elevated, but free thyroxine (fT4) concentrations were within the reference range at the time of diagnosis (at two and six months of age), indicating compensated hypothyroidism. During the follow-up, both cases needed an increasing dose of $\mathrm{T} 4$ supplementation to maintain $\mathrm{TSH}$ at normal levels. Despite the adequate T4 replacement, one of the twins had a mild developmental delay, probably due to the premature birth. In the T4 withdrawal test at three years of age, serum TSH levels rose markedly over the reference value, and
fT4 levels decreased but remained in the reference range in both cases. Their mother had a goiter and fluctuations in TFTs, but did not require any T4 medication. Additionally, two TSHR variants, Pro52Thr and Asp36His, were identified among the study subjects, but they were predicted to reflect polymorphisms without functional consequences (13).

Family F11 (Fig. 1) included two children with CH. Both affected individuals were found to carry a heterozygous PAX8 c.91C $>$ T, p.R31C mutation causing an amino acid change in the PAX8 protein (Table 2 ). The detected arginine to cysteine mutation at position 31 leads to a loss of structuralfunctional constraints and intermolecular contacts to the DNA response element and thus a loss of functionality (Fig. 3). Both cases showed serum TSH levels $>200 \mathrm{mIU} / \mathrm{L}$, fT4 was in the low range of the reference values, and they had a small or hypoplastic thyroid gland evaluated by ultrasound. In addition, one of the affected patients had a right kidney agenesis. The father was diagnosed with nonautoimmune hypothyroidism at 30 years of age, and sequencing of $P A X 8$ revealed that he was also a carrier of the $P A X 8$ c. $91 \mathrm{C}>\mathrm{T}$ mutation. The mother and other siblings had normal TFTs and no alteration in the $P A X 8$ sequence. In line with the modeling, the in vitro tests demonstrated that the transcriptional activity of the $P A X 8$ mutant was almost completely lost compared with the WT protein (Fig. 3).

The details of the mutations among the familial cases are described in Table 2. Four families (Fig. 1) with hereditary $\mathrm{CH}$ had no significant mutations in the target genes. However, in one family (F6) with goitrous $\mathrm{CH}$, the index case had a rare novel heterozygous $T G$ mutation. It introduced a premature stop of translation at position 655 of the TG protein and is predicted to be pathogenic based on the in silico analysis. However, it was not segregating with the phenotype, but present in the healthy father, and not in the other affected sibling.

\section{Results from the sporadic $\mathrm{CH}$ cohort}

The sporadic cohort included $\mathrm{CH}$ patients with a normal thyroid, hypoplasia, or agenesis of the thyroid. Four patients suffered from respiratory distress syndrome (RDS) or mild respiratory problems at birth. Furthermore, three cases were diagnosed with minor heart malformations, including ventricular septal defect (VSD), persistent ductus arteriosus (PDA), and persistent foramen ovale (PFO). Otherwise, the patients did not have other significant diagnoses, and they did not suffer from developmental problems (Table 3).

Among these cases, one patient with a typical brain-lungthyroid syndrome had nearly lethal RDS and pulmonary dysfunction at birth (Tables 3 and 4, \#73). In the sequencing analysis, the $N K X 2.1$ sequence was normal. Due to the typical phenotype, the presence of haploinsufficiency was tested with multiplex ligation-dependent gene analysis (MLPA), which revealed a large hemiallelic deletion covering all three exons. In further analysis, a larger $1.1 \mathrm{Mb}$ microdeletion was detected in location 14q13q21.1. This de novo deletion included six protein-coding genes (SFTA3, NKX2.1, NKX2.8, $P A X 9$, SLC25A21, and MIPOL1). Despite adequate and prompt T4 replacement, the patient developed severe mental and motor retardation, and required continuous medication for interstitial lung disease. The parents had no thyroid or genetic abnormalities. In addition to this large hemiallelic 
A

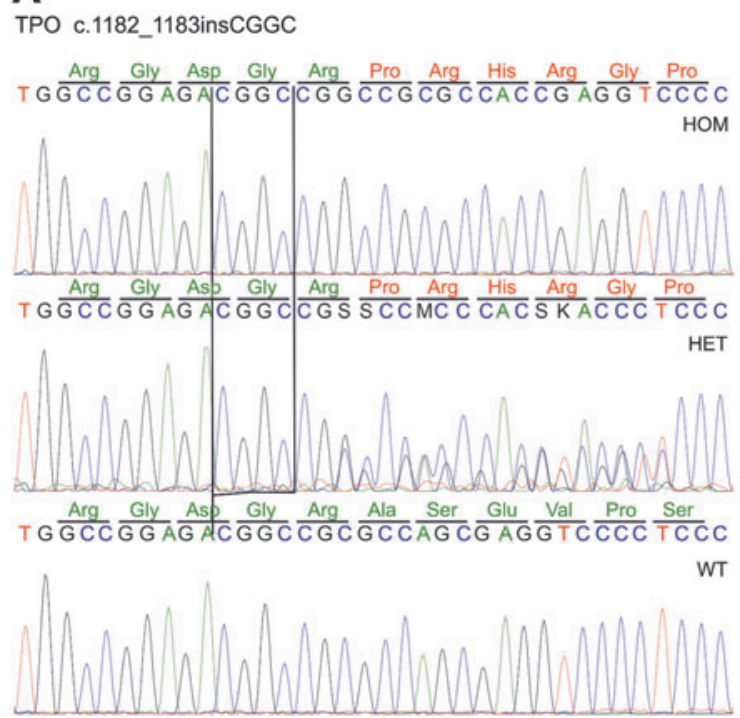

B
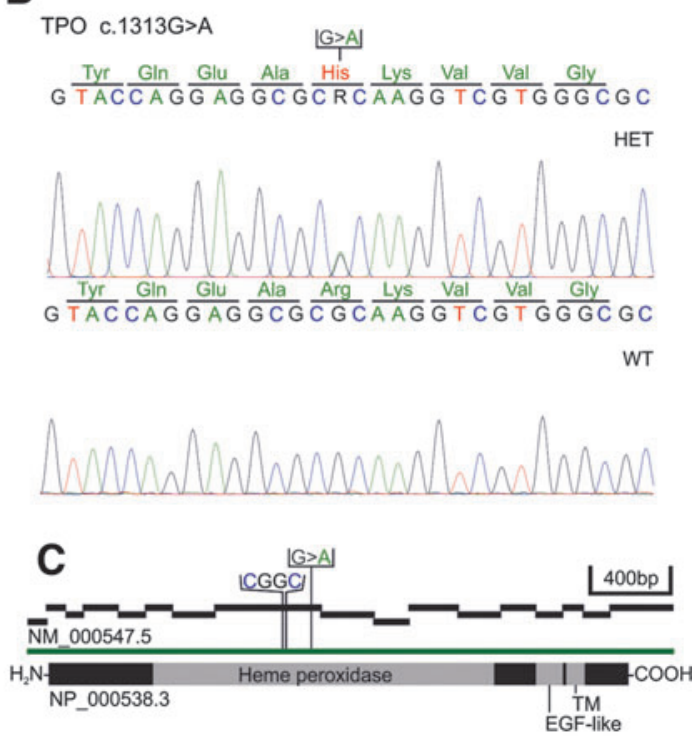

D

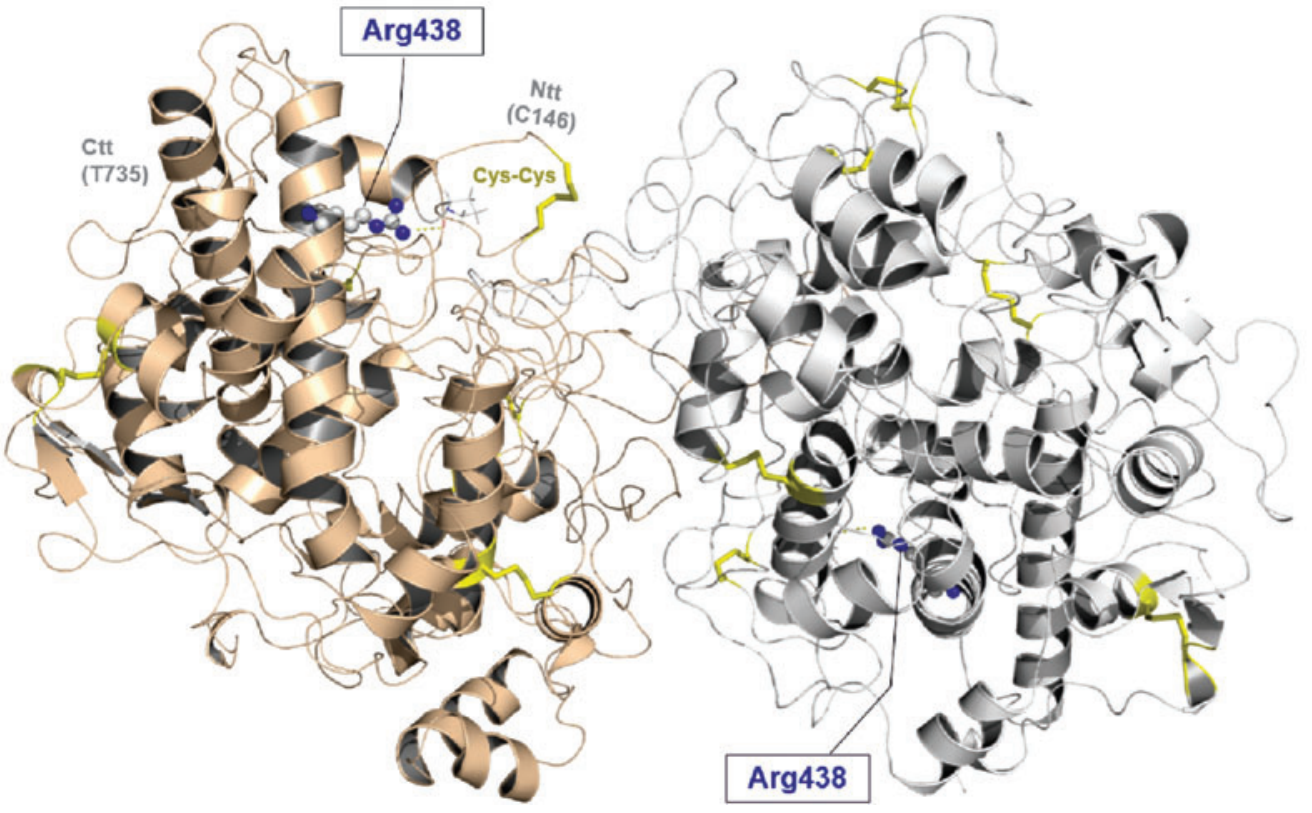

FIG. 2. Confirmation of the TPO mutations identified from familial cases by Sanger sequencing and protein modeling. Sanger chromatograms of (A) the heterozygous (HET) and homozygous (HOM) TPO c.1182_1183insCGGC mutant and (B) $T P O$ c.1313G $>$ A point mutation compared with WT sequence. (C) A schematic picture of $\bar{T} P O$ with the localization of the mutations. (D) Dimeric model of the myeloperoxidase-like domain of TPO based on a homologous dimeric structure of myeloperoxidase. The homology model contains residues from Cys146-Thr735, whereby only the backbone is visualized (ribbon-tube cartoon). The TPO protomers are colored differently (the heme group, ions, and glycosylations are not represented). Cysteine disulfide-bridges (yellow sticks) are involved in maintaining the quaternary structure. TM, transmembrane domain. The side-chain of arginine at position 438 is connected via an $\mathrm{H}$-bond to the loop-backbone at proline 153 and functions in consequence as a structural constraint between both domain fragments. The histidine mutant at position 438 likely fails establishing this important intramolecular interaction and leads to modification of the structural adjustment inside the domain.

NKX2.1 deletion, two additional novel $N K X 2.1$ variants were detected. One sporadic $\mathrm{CH}$ patient (Tables 3 and 4, \#71) had a small 9 bp deletion, c.793_801del, in $N K X 2.1$. The patient was born premature at week 36 and required respiratory support at the newborn intensive care unit for two days, but no additional lung or neurological phenotype became apparent after the newborn period. The 9 bp deletion c.793_801del, p.G264- 266del leads to the removal of three glycine residues from the glycine-rich area of the protein. However, the deletion had no impact on the transactivation of the $T G$ promoter, as shown by a luciferase reporter assay (Supplementary Fig. S2). Moreover, the deletion was present in the father with normal TFTs and no sign of thyroid autoimmunity. Furthermore, a patient with elevated TSH levels, fT4 levels at reference range, and thyroid 
A

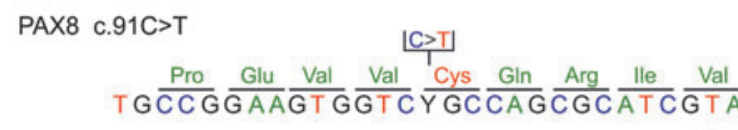

HET
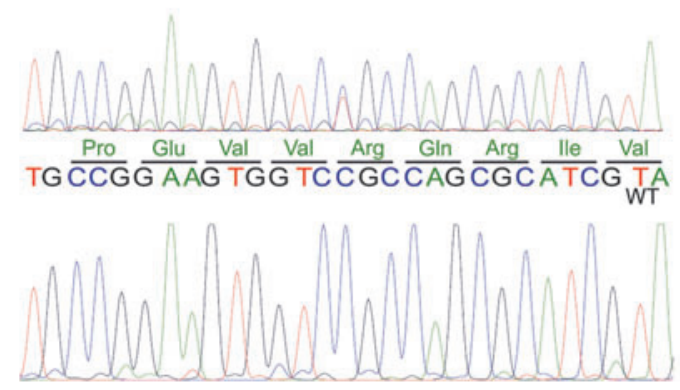

B

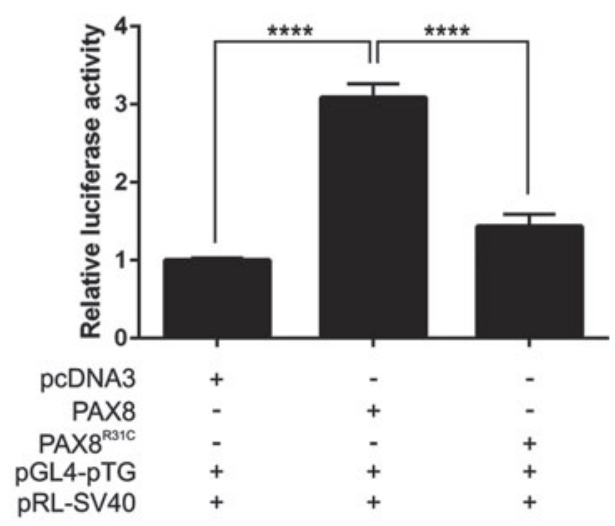

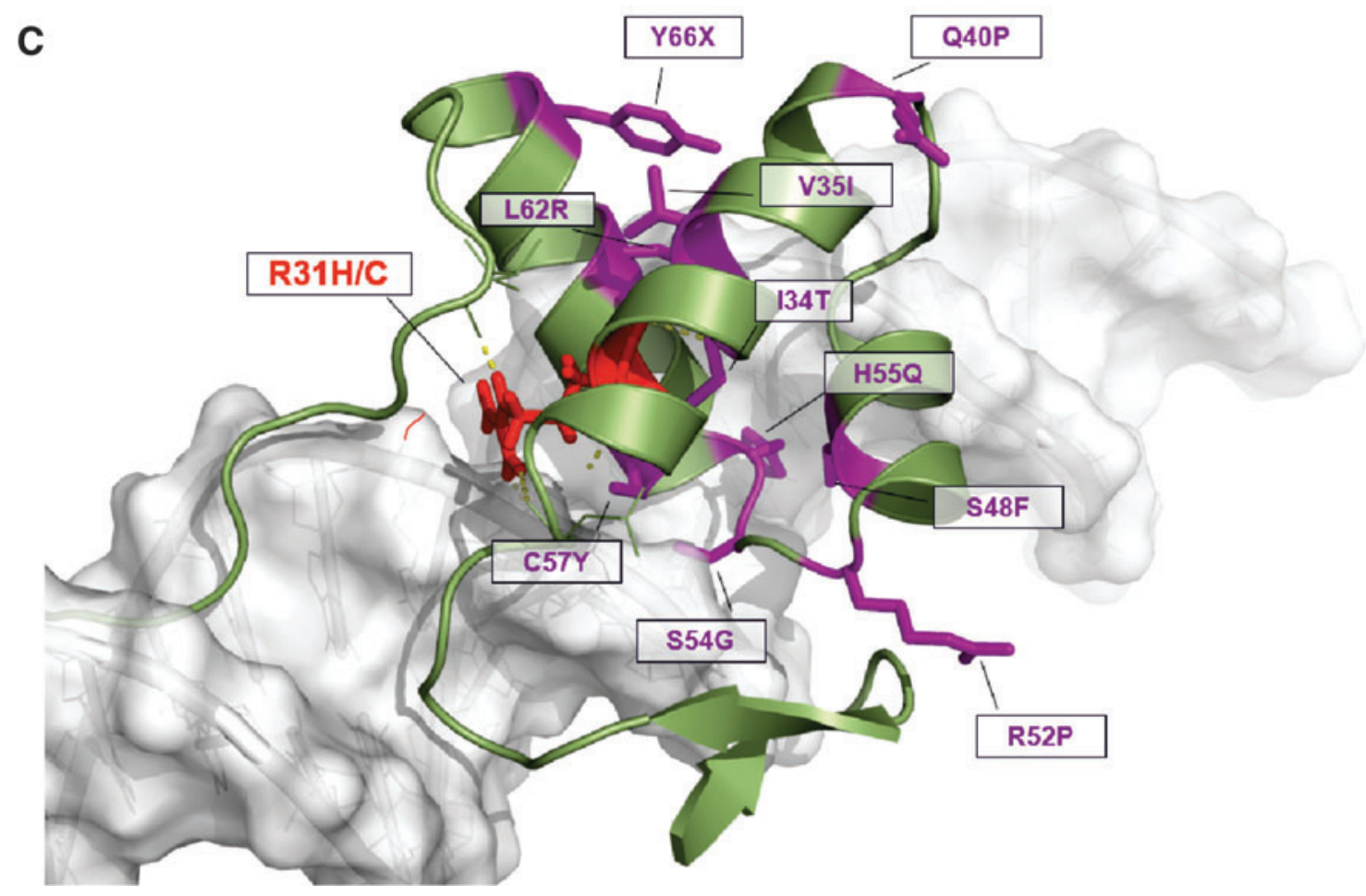

FIG. 3. Characterization of the $P A X 8 \mathrm{R} 31 \mathrm{C}$ mutation in a familial $\mathrm{CH}$ case. (A) Sanger chromatogram visualizing the mutated allele in this family. (B) A loss of transactivation activity of the PAX8 R31C mutant compared with wild type using a $T G$ promoter luciferase reporter assay. Bars represent means \pm standard error of the mean from experiments performed on three separate days $(n=15 ; * * * * \leq 0.0001)$. (C) Three-dimensional PAX8 model with highlighted arginine at position 31. The crystallized $P A X 5$ structure (backbone presentation green) together with a DNA response element (white backbone and translucent surface) was used to model $P A X 8$ protein fragments. Examples of other known pathogenic $P A X 8$ mutations are labeled with magenta sticks. Mutations at the hydrophobic inner core disturb the tight package between the helixes (such as Ile34Thr or Cys57Tyr). An intermolecular H-bond from Arg31 contacts the DNA and mediates the proper justification of the protein and the DNA toward each other.

hemiagenesis was included in the genetic analysis (Tables 3 and 4, \#40). Interestingly, he was carrying a c.313G $>$ A missense mutation (p.V105M) in $N K X 2.1$, but the mutation was present also in the healthy parent, and it did not affect the transactivation of the $T G$ promoter, indicating this mutation is most likely benign (Supplementary Fig. S2).

Rather unexpectedly, several rare $T G$ mutations were observed in our sporadic $\mathrm{CH}$ cohort. In one case with permanent and apparently sporadic $\mathrm{CH}$ (Tables 3 and 4,\#77), compound heterozygous mutations were identified in $T G$. Both parents carried one of the mutations and had normal TFTs. The c.1963 C > T mutation, p.Q655*, also observed in a familial case (Fig.1, F6, \#13), caused a premature stop of translation at position 655 of the TG protein. The other $T G$ mutation c.4378G $>$ A, p.V1460I is also rare (MAF <0.0003) and predicted to be highly pathogenic in standard protein function prediction programs. The serum TG levels in this patient were undetectable, and no goiter was seen in a computed tomography scan of the neck at birth or 
Table 3. Clinical Characteristics of the Sporadic Cohort

\begin{tabular}{|c|c|c|c|c|c|c|c|}
\hline No. & $\begin{array}{c}u T S H / \\
u T 4 / f T 4\end{array}$ & TSH & $f T 4$ & $T G$ & $\begin{array}{l}\text { Dysfunction, } \\
\text { morphology }\end{array}$ & $\begin{array}{c}\text { Age (days), } \\
\text { sex }\end{array}$ & $\begin{array}{l}\text { Other diagnosis, } \\
\text { affected family } \\
\text { members }\end{array}$ \\
\hline 42 & $240 /-$ & 270 (3 days) & 10.3 (3 days) & - & $\mathrm{CH},-$ & $0, \mathrm{~F}$ & RDS \\
\hline 54 & $373 /-$ & $>100$ (3 days) & 6.0 (3 days) & - & $\mathrm{CH},-$ & $0, \mathrm{M}$ & - \\
\hline 55 & $880 / 4 /-$ & $>100$ (3 days) & $<3.0$ (3 days) & - & $\mathrm{CH},-$ & $0, \mathrm{M}$ & Hyperbilirubinemia \\
\hline 56 & $530 /-$ & 550 (4 days) & 8.2 (4 days) & 1.86 & $\mathrm{CH},-$ & $0, \mathrm{~F}$ & - \\
\hline 57 & $44 / 108 / 13.8$ & 23 (3 days) & 25.1 (3 days) & 9.66 & $\mathrm{CH},-$ & $0, \mathrm{M}$ & $\begin{array}{l}\text { Transient tachypnea, } \\
\text { hypoglygemia }\end{array}$ \\
\hline 59 & $83 /-$ & 64 (3 days) & 20.4 (3 days) & 4.8 & $\mathrm{CH},-$ & $0, \mathrm{~F}$ & $\begin{array}{l}\text { VSD, M has abnormal } \\
\text { TFTs and anomalic } \\
\text { thyroid }\end{array}$ \\
\hline 70 & $111 /-$ & - & - & - & CH, hypoplasia & $0, \mathrm{M}$ & - \\
\hline 71 & $520 /-$ & 258 (3 days) & 14.4 (3 days) & - & $\mathrm{CH}$, agenesis & $0, \mathrm{~F}$ & Prematurity $(36+0)$ \\
\hline 73 & $400 /-$ & 170 (3 days) & $<5.2$ (3 days) & - & $\mathrm{CH},-$ & $0, \mathrm{M}$ & $\begin{array}{l}\text { RDS, PH, interstitial } \\
\text { lung disease, mental } \\
\text { and retardation }\end{array}$ \\
\hline 77 & $84 /-$ & 78 (3 days) & $19.5(3 d)$ & $<0.05$ & $\mathrm{CH}$, normal & $0, \mathrm{~F}$ & PDA, PFO \\
\hline 78 & $88 / 113 / 10.8$ & 53 (3 days) & $15.8(3 d)$ & 0.89 & $\mathrm{CH},-$ & $0, \mathrm{M}$ & - \\
\hline 90 & $250 / 83 /-$ & 375 (8 days) & - & - & $\mathrm{CH}$, agenesis & $0, \mathrm{~F}$ & VSD, M thyroid $\mathrm{Ca}$ \\
\hline 92 & $12 /-$ & 13 (13 days) & $14.8(13 \mathrm{~d})$ & - & $\mathrm{CH}$, hypoplasia & $27, \mathrm{M}$ & Gemini \\
\hline 99 & $315 / 67 / 7.8$ & 380.9 (2 days) & $7.5(2 \mathrm{~d})$ & 2.19 & $\mathrm{CH}$, normal & $0, \mathrm{~F}$ & Asthma \\
\hline 103 & $670 / 116 / 12$ & 250 (3 days) & $16.3(3 \mathrm{~d})$ & 4.99 & $\mathrm{CH},-$ & $0, \mathrm{M}$ & - \\
\hline 39 & $9 /-$ & 9.1 & 16.1 & - & hyperTSH, - & 5 months, $\mathrm{F}$ & $\begin{array}{l}\text { Mild developmental } \\
\text { delay }\end{array}$ \\
\hline 40 & $16 /-$ & 8.3 (5 years $)$ & $15.4(5 y)$ & - & $\begin{array}{l}\text { hyperTSH, } \\
\text { hemiagenesis }\end{array}$ & 5 years, $M$ &,$- \mathrm{M}$ has $\mathrm{AIH}$ \\
\hline
\end{tabular}

Reference values: uTSH/uT4/fT4 (<40 mIU/L, >120 nM/L, >10 pmol/L); control TSH and fT4 at 3 days old 0.4-6 mIU/L and 9-19 pmol/ $\mathrm{L}$, serum TG levels $3.5-56 \mu \mathrm{g} / \mathrm{L}$.

$\mathrm{uTSH} / \mathrm{uT} 4 / \mathrm{fT} 4=$ hormone levels measured at birth from umbilical cord; TSH and fT4=confirmation of the positive screening values (age in parentheses).

uTSH, umbilical thyrotropin; uT4, umbilical thyroxine; fT4, free thyroxine; TG, thyroglobulin; RDS, respiratory distress syndrome; VSD, ventricular septal defect; TFTs, thyroid function tests; PH, pulmonary hypertension; PDA, persistent ductus arteriosus; PFO, persistent foramen ovale; $\mathrm{M}$, mother; $\mathrm{Ca}$, carcinoma; $\mathrm{AIH}$, autoimmune thyroid disease.

Table 4. Detailed Information and Classification of Variants Identified from Sporadic CH Cases

\begin{tabular}{|c|c|c|c|c|c|c|c|}
\hline No. & Gene & GeneBank & Base change & Protein change & ExAC MAF & Read depth & Classification \\
\hline 42 & SLC26A4 & NM_000441.1 & $1796 C>T$ & A599V & 0.00019 & 915 & B \\
\hline 42 & $N K X 2.5$ & NM_001166176.1 & c. $428 \mathrm{G}>\mathrm{A}$ & R143Q & 0.00082 & 994 & $\mathbf{C}$ \\
\hline 55 & SLC26A4 & NM-000441.1 & c. $1363 \mathrm{~A}>\mathrm{T}$ & $\mathrm{I} 455 \mathrm{~F}$ & - & 640 & $\mathrm{C}$ \\
\hline 56 & DUOX1 & NM_017434 & c. $656 \mathrm{C}>\mathrm{T}$ & P219L & 0.00010 & 989 & $\mathrm{C}$ \\
\hline 57 & $T G$ & NM_003235.4 & c. $353 \mathrm{C}>\mathrm{T}$ & P118L & 0.01471 & 510 & $\mathrm{C}$ \\
\hline 57 & DUOX2 & NM_014080.4 & c. $908 \mathrm{C}>\mathrm{G}$ & P303R & 0.01067 & 564 & $\mathrm{~B}$ \\
\hline 59 & SLC26A4 & NM_000441.1 & c. $2326 \mathrm{C}>\mathrm{T}$ & R776C & 0.00200 & 496 & $\mathrm{C}$ \\
\hline 71 & NKX2.1 & NM_001079668 & c.793_801del & G264-266del & - & - & $\mathbf{C}^{\#}$ \\
\hline 73 & $N K X 2.1$ & NM_001079668 & hemidel & - & - & - & $\mathbf{A}$ \\
\hline 77 & $T G$ & NM_003235.4 & c. $1963 C>T$ & Q655* & 0.00013 & 329 & B \\
\hline 77 & $T G$ & NM_003235.4 & c. $4378 \mathrm{G}>\mathrm{A}$ & V1460I & 0.00020 & 182 & B \\
\hline 90 & $D U O X 2$ & NM_014080.4 & c.518A $>G$ & A173S & - & 997 & $\mathbf{C}$ \\
\hline 99 & $T G$ & NM_003235.4 & c. $6130 \mathrm{C}>\mathrm{T}$ & R2044C & 0.00005 & 996 & B \\
\hline 99 & $T G$ & NM_003235.4 & c. $5921 \mathrm{~T}>\mathrm{C}$ & M1974T & 0.08417 & 999 & $\mathrm{C}^{\#}$ \\
\hline 103 & SLC26A4 & NM_000441.1 & c. $1790 \mathrm{~T}>\mathrm{C}$ & L597S & 0.00826 & 988 & $\mathrm{~B}$ \\
\hline 103 & $T G$ & NM_003235.4 & c.3416C $>$ T & S1139L & 0.00030 & 719 & B \\
\hline 39 & $T R H$ & NM_007117.4 & c. $212 \mathrm{C}>\mathrm{T}$ & A71V & 0.00039 & 997 & $\mathrm{C}^{\#}$ \\
\hline 39 & $T S H R$ & NM_000369.2 & c. $106 \mathrm{G}>\mathrm{C}$ & D36H & 0.00602 & 966 & $\mathrm{C}^{\#}$ \\
\hline 40 & $N K X 2.1$ & NM_001079668 & c.313G $>$ A & V105M & - & - & $\mathbf{C}^{\#}$ \\
\hline
\end{tabular}

Novel mutations in known $\mathrm{CH}$ genes shown in bold.

$\mathrm{A}$, pathogenic mutation (based on segregation, literature, and in vitro experiments); $\mathrm{B}$, likely pathogenic mutation (predicted pathogenicity in silico analysis); $\mathrm{C}$, functional effect unclear; $\mathrm{C}^{\#}$, likely benign mutation (based on in vitro test and/or segregation); *, stop codon. 
observed during follow-up. The other case with nongoitrous $\mathrm{CH}$ (Tables 3 and 4, \#99) had a low frequency novel heterozygous c.6130C > T, p.R2044C TG mutation (present in 1/6614 alleles in the Finnish population), which is predicted to be pathogenic in silico. The adjustment of the filtering parameters of the NGS analysis and search for compound heterozygous variants in the $T G$ gene revealed another c.5921T $>C$, p. M1974T missense variant in this case. However, there are several cases with homozygosity for this allele in the ExAC database. The variant, although present in only $6 \%$ of the Finnish population is present in fairly high frequency in certain populations, indicating that it is probably a polymorphism. The healthy parents were carriers of one of the mutations. Additionally, a combination of rare heterozygous $T G$, p.S1139L, and SLC26A4, p.L597S mutations was present in a sporadic case with normal thyroid gland (Tables 3 and 4,\#103). The extended family history revealed that he had two other $\mathrm{CH}$ cases in the distant family, but DNA could not be obtained from these patients.

A few rare and likely pathogenic heterozygous $D U O X 2$ (p.P303R and novel p.A173S) and SLC26A4 (p.I455F, p.R776C, p.L597S, and a novel p.A599V) variants were present among the study subjects (Table 4). A search for more common compound heterozygous variants was then performed, but the segregation or pathogenicity of these mutants could not be confirmed. Sanger sequencing of the DUOXA2 exons from patients with DUOX2 mutations did not reveal any novel mutations either.

\section{Discussion}

To date, more than 15 causative genes have been linked to $\mathrm{CH}$. The large number of genes poses a challenge to select target genes for Sanger sequencing. The initially subtle clinical phenotype and the lack of detailed diagnostic tests, which are often not performed routinely, may hamper the selection of possible target genes.

The present study established a high-throughput NGS panel to enable cost-effective, efficient, and multigenic screening covering nearly all known $\mathrm{CH}$ target genes. To the best of the authors' knowledge, such a broad screening has not been reported in $\mathrm{CH}$ previously. Using this panel, molecular causes for $\mathrm{CH}$ were identified in $6 / 11$ families with different forms of familial $\mathrm{CH}$. Furthermore, several pathogenic and likely pathogenic mutations were found among sporadic cases. Due to the high coverage of the NGS screen, it is unlikely to have missed any mutations among the exons of the candidate genes in the remaining five families with negative findings. Hence, these families may perhaps carry intronic mutations, larger deletions in the respective gene areas, or novel $\mathrm{CH}$ gene mutations, which are not detected by the current panel. As demonstrated in this study by the patient with typical brain-lung-thyroid syndrome, and also shown in other studies (11), a common pitfall of the NGS and conventional sequencing is that larger deletion(s) will go unnoticed. Hence, recognizing these deletions requires other methods such as multiplex ligation-dependent gene analysis or comparative genomic hybridization techniques, which should be considered in specific cases. Identification of the deletions or insertions in NGS data analysis is challenging, and the common algorithms for recognizing them yields variable results and are not yet in standard use (14).
In the familial cases, pathogenic mutations were found in the TPO, PAX8, and TSHR genes. Interestingly, the TPO frameshift mutation leading to an early truncation of the protein was present in four of these families. When present in a homozygous form, this mutation has been shown to inactivate the TPO function completely, which results in elevated TSH, low serum T4 levels, and nearly total release of iodine in the perchlorate test (15). Similar mutations in this region have been described and shown to be the most prevalent cause for thyroid dyshormogenesis in several populations (15-17). Although the TPO mutations are typically associated with thyroid goiter, no goiter was observed among of our homozygous TPO c.1182_1183insCGGC patients or in their heterozygous parents. Thus, other factors such as dietary iodine supply, efficacy of the thyroxine replacement, or other genetic findings may be involved in this phenotype. In two affected cousins with heterozygous TPOfs mutations, one carried another novel TPO missense mutation, $R 438 H$, which most likely explains the phenotype. The insights from TPO homology models suggested that the $R 438 H$ mutation likely impairs the enzymatic function by modification of the intramolecular structure (Fig. 2D). The secondary and quaternary structure of the enzyme might be modified due to interruption of essential H-bonds important for structural adjustments. However, in the other case, no additional TPO mutations could be detected. This may be due to another pathogenic mutation located in the promoter or intron areas, which were not covered by the panel, or, for example, due to monoallelic expression of the mutant gene, as suggested by Fuggazola et al. (18).

NKX2.1 is a transcription factor playing an important role in thyroid development. Additionally, it has a crucial impact on brain and lung development. Typically, the patients with impaired NKX2.1 function have both severe pulmonary and neurological symptoms $(11,19)$. None of the familial cases had any typical brain-lung-thyroid phenotype. In line with this, no alteration in $N K X 2.1$ was found among the hereditary cases. In contrast, a sporadic case with severe pulmonary dysfunction and neurological symptoms was found to carry a large hemiallelic deletion in the $N K X 2.1$ area in further analysis, although the $N K X 2.1$ sequence appeared normal in the initial screening. This highlights the importance of using alternative methods to exon sequencing alone in the genetic analysis of patients suspected with this $\mathrm{CH}$ phenotype. Interestingly, two novel alterations were detected in $N K X 2.1$ in the cohort. One case showed mild respiratory adaptation problems at birth without any further lung phenotype, and the other case had non-autoimmune hypothyroidism and hemiagenesis, but no additional phenotypic features. However, the in vitro TG transactivation tests indicate that the c.313G $>$ A missense and the c.793_801del deletion mutants do not have any effect on the transactivation of the $T G$ promoter compared to wild-type $N K X 2.1$. Moreover, the presence of the variants in healthy parents suggested that these were most likely benign. However, only the transactivation activity of these mutants was tested, and therefore the possibility that the $N K X 2.1$ mutations could affect NKX2.1 protein interactions, for example, cannot be excluded.

The heterozygous $P A X 8$ mutation $\mathrm{R} 31 \mathrm{H}$ was one of the original $P A X 8$ mutations described and shown to lack DNA binding activity in vitro (20). Here, a family with another heterozygous mutation, R31C, at this position was identified. The two siblings have $\mathrm{CH}$ and a hypoplastic thyroid, and one of them also has a unilateral kidney agenesis. Based on the 
protein modeling (Fig. 3) and transactivation assay, this PAX8 $\mathrm{R} 31 \mathrm{C}$ mutation seems to inactivate the transcription factor activity completely, as reported previously for the $\mathrm{R} 31 \mathrm{H}$ mutation (21-23), suggesting that this codon is a mutational hot spot.

Loss-of-function mutations in the TSHR have been reported as a common cause of $\mathrm{CH}$ in several populations (24). Contrary to gain-of-function mutations, which are always heterozygous, the occurrence of inactivating TSHR mutations can be heterozygous, compound heterozygous, or homozygous $(25,26)$. In the present cohort, twins were identified harboring a R519C TSHR mutation in transmembrane helix (TMH) 3. Position R519 is highly conserved within family A of Gprotein coupled receptors (27). In line with this, the functional characterization of TSHR R519C and R519G mutants in the study by Tsunekawa et al. demonstrated reduced ligand binding and impaired activation of $\mathrm{G}_{\mathrm{s} \alpha}$ and $\mathrm{G}_{\mathrm{q} / 11}$ compared with the wild-type receptor (28). In addition, several studies suggested that heterozygous inactivating mutations may be associated with $\mathrm{CH}$ and that the mutant TSHR could have a dominant negative effect on the activity of the wild-type receptor (29). This occurs mainly via intracellular entrapment of the TSHR dimer/oligomer between wild-type and mutated receptors, which are formed shortly after translation.

Mutations in $T G$ are a common cause of $\mathrm{CH}$, often resulting in the development of a large goiter in the affected cases. Unexpectedly, among the 11 pedigrees with familial $\mathrm{CH}$, no disease causing $T G$ mutations was found. In one family with goitrous $\mathrm{CH}$, a heterozygous $T G$ variant was identified in two children, but it was not segregating with the phenotype in the family, nor was any other variant of TG detected. Surprisingly, a few likely pathogenic monoallelic $T G$ mutations were found in apparently sporadic $\mathrm{CH}$ patients. In two cases, the $\mathrm{CH}$ was most probably caused by rare compound heterozygous mutations in $T G$.

Two rare DUOX2 mutations were found in sporadic cases. The DUOX2 p.P303R mutation has previously been shown to have a slightly lower activity compared to the wild type (30). However, no other mutation could be identified in DUOX2 or in DUOXA2 in this patient. The DUOX2 p.A173S variant has not been reported previously to the best of the authors' knowledge. These mutations were monoallelic, and we could not obtain samples from relatives to confirm segregation with the phenotype, which makes it challenging to draw conclusions regarding these variants.

The rare SLC26A4 variants that were detected (p.A599V, p.I455F, p.R776C, and p.L597S) from the CH cases have partly been characterized before. Both the p.L597S and the p.R776C mutants have been detected in Pendred syndrome cases, but the functionality seems to be indistinguishable from the wild-type protein, and the pathogenicity of these mutations is therefore unclear $(31,32)$. The p.I455F mutant has been found in a heterozygous state in controls with normal hearing (33). To the authors' knowledge, the p.A599V variant has not been detected before in cases with $\mathrm{CH}$ or Pendred syndrome.

In summary, the targeted NGS panel of nearly all currently known $\mathrm{CH}$ genes provides an efficient, cost-effective, and multigenic screening tool for gene mutations in the coding region of these genes. It may be an additional tool for clinicians to identify the genetic etiology accurately of the selected $\mathrm{CH}$ patients in the future, especially in dyshormogenic, familial, and syndromic $\mathrm{CH}$ cases. Moreover, it may serve as a valuable prescreening method prior to exome or genome analyses.

\section{Acknowledgments}

We thank Harri Niinikoski, Kirsti Näntö-Salonen, Anne Maarit Haavisto, and Tiina Kultti for their help obtaining the patient samples; Jasmiina Laurila and Meeri Jännäri for laboratory assistance; and Vidal Fey for his help with evaluation of the sequence data. The study was supported by the Finnish Cultural Foundation (C.L.), Medicinska Understödsföreningen Liv \& Hälsa r.f (C.L.), Finnish Academy of Science (J.K.), Finnish Pediatric and Medical Foundations (J.K.), EVO grant from Turku University Hospital, and The Finnish Medical Foundation (J.K.).

\section{Author Disclosure Statement}

The authors declare no conflicts of interest.

\section{References}

1. Harris KB, Pass KA 2007 Increase in congenital hypothyroidism in New York State and in the United States. Mol Genet Metab 91:268-277.

2. Deladoey J, Ruel J, Giguere Y, Van Vliet G 2011 Is the incidence of congenital hypothyroidism really increasing? A 20-year retrospective population-based study in Quebec. J Clin Endocrinol Metab 96:2422-2429.

3. Toublanc JE 1992 Comparison of epidemiological data on congenital hypothyroidism in Europe with those of other parts in the world. Horm Res 38:230-235.

4. Arnold KA, Bapat V, Bennett A, Bigos ST, Bode HH, Brown R, Crawford JD, Crigler JF, Fox S, Friedman E, Genel M, Gertner J, Haag BL, Haddow JE, Hartz S, Kovac M, LaMarche P, Larsen PR, La Vecchio F, Leonard M, MacCracken J, Mitchell ML, O'Brien K, Page LA, Phelan J, Potischman N, Ratzan S, Reed H, Reiter E, SadeghiNejad A, Senior B, Sposata S, Tamborlane WV, Walter R, Klein RZ 1981 Effects of neonatal screening for hypothyroidism: prevention of mental retardation by treatment before clinical manifestations. New England congenital hypothyroidism collaborative. Lancet 2:1095-1098.

5. Reddy PA, Rajagopal G, Harinarayan CV, Vanaja V, Rajasekhar D, Suresh V, Sachan A 2010 High prevalence of associated birth defects in congenital hypothyroidism. Int $\mathrm{J}$ Pediatr Endocrinol 2010:940980.

6. Castanet M, Polak M, Bonaiti-Pellie C, Lyonnet S, Czernichow P, Leger J 2001 Nineteen years of national screening for congenital hypothyroidism: familial cases with thyroid dysgenesis suggest the involvement of genetic factors. J Clin Endocrinol Metab 86:2009-2014.

7. Leger J, Marinovic D, Garel C, Bonaiti-Pellie C, Polak M, Czernichow P 2002 Thyroid developmental anomalies in first degree relatives of children with congenital hypothyroidism. J Clin Endocrinol Metab 87:575-580.

8. Park SM, Chatterjee VK 2005 Genetics of congenital hypothyroidism. J Med Genet 42:379-389.

9. Persani L 2012 Clinical review: Central hypothyroidism: pathogenic, diagnostic, and therapeutic challenges. J Clin Endocrinol Metab 97:3068-3078.

10. Virtanen M, Perheentupa J, Maenpaa J, Pitkanen L, Pikkarainen J 1984 Finnish national screening for hypothyroidism. Few false positives, early therapy. Eur J Pediatr 143:2-5.

11. Thorwarth A, Schnittert-Hubener S, Schrumpf P, Muller I, Jyrch S, Dame C, Biebermann H, Kleinau G, Katchanov J, Schuelke M, Ebert G, Steininger A, Bonnemann C, 
Brockmann K, Christen HJ, Crock P, deZegher F, Griese M, Hewitt J, Ivarsson S, Hubner C, Kapelari K, Plecko B, Rating D, Stoeva I, Ropers HH, Gruters A, Ullmann R, Krude H 2014 Comprehensive genotyping and clinical characterisation reveal 27 novel NKX2-1 mutations and expand the phenotypic spectrum. J Med Genet 51:375-387.

12. Runkle EA, Rice SJ, Qi J, Masser D, Antonetti DA, Winslow MM, Mu D 2012 Occludin is a direct target of thyroid transcription factor-1 (TTF-1/NKX2-1). J Biol Chem 287: 28790-28801.

13. Tonacchera M, Perri A, De Marco G, Agretti P, Banco ME, Di Cosmo C, Grasso L, Vitti P, Chiovato L, Pinchera A 2004 Low prevalence of thyrotropin receptor mutations in a large series of subjects with sporadic and familial nonautoimmune subclinical hypothyroidism. J Clin Endocrinol Metab 89:5787-5793.

14. Ghoneim DH, Myers JR, Tuttle E, Paciorkowski AR 2014 Comparison of insertion/deletion calling algorithms on human next-generation sequencing data. BMC Res Notes 7:864.

15. Bakker B, Bikker H, Vulsma T, de Randamie JS, Wiedijk BM, De Vijlder JJ 2000 Two decades of screening for congenital hypothyroidism in The Netherlands: TPO gene mutations in total iodide organification defects (an update). J Clin Endocrinol Metab 85:3708-3712.

16. Abramowicz MJ, Targovnik HM, Varela V, Cochaux P, Krawiec L, Pisarev MA, Propato FV, Juvenal G, Chester HA, Vassart G 1992 Identification of a mutation in the coding sequence of the human thyroid peroxidase gene causing congenital goiter. J Clin Invest 90:1200-1204.

17. Cangul H, Aycan Z, Olivera-Nappa A, Saglam H, Schoenmakers NA, Boelaert K, Cetinkaya S, Tarim O, Bober E, Darendeliler F, Bas V, Demir K, Aydin BK, Kendall M, Cole T, Hogler W, Chatterjee VK, Barrett TG, Maher ER 2013 Thyroid dyshormonogenesis is mainly caused by TPO mutations in consanguineous community. Clin Endocrinol (Oxf) 79:275-281.

18. Fugazzola L, Cerutti N, Mannavola D, Vannucchi G, Fallini C, Persani L, Beck-Peccoz P 2003 Monoallelic expression of mutant thyroid peroxidase allele causing total iodide organification defect. J Clin Endocrinol Metab 88:3264-3271.

19. Krude H, Schutz B, Biebermann H, von Moers A, Schnabel D, Neitzel H, Tonnies H, Weise D, Lafferty A, Schwarz S, DeFelice M, von Deimling A, van Landeghem F, DiLauro R, Gruters A 2002 Choreoathetosis, hypothyroidism, and pulmonary alterations due to human NKX2-1 haploinsufficiency. J Clin Invest 109:475-480.

20. Macchia PE, Lapi P, Krude H, Pirro MT, Missero C, Chiovato L, Souabni A, Baserga M, Tassi V, Pinchera A, Fenzi G, Gruters A, Busslinger M, Di Lauro R 1998 PAX8 mutations associated with congenital hypothyroidism caused by thyroid dysgenesis. Nat Genet 19:83-86.

21. Ramos HE, Carre A, Chevrier L, Szinnai G, Tron E, Cerqueira TL, Leger J, Cabrol S, Puel O, Queinnec C, De Roux N, Guillot L, Castanet M, Polak M 2014 Extreme phenotypic variability of thyroid dysgenesis in six new cases of congenital hypothyroidism due to PAX8 gene loss-offunction mutations. Eur J Endocrinol 171:499-507.

22. Komatsu M, Takahashi T, Takahashi I, Nakamura M, Takahashi I, Takada G 2001 Thyroid dysgenesis caused by PAX8 mutation: the hypermutability with $\mathrm{CpG}$ dinucleotides at codon 31. J Pediatr 139:597-599.

23. Liu SG, Zhang SS, Zhang LQ, Li WJ, Zhang AQ, Lu KN, Wang MJ, Yan SL, Ma X 2012 Screening of PAX8 muta- tions in Chinese patients with congenital hypothyroidism. J Endocrinol Invest 35:889-892.

24. Labadi A, Grassi ES, Gellen B, Kleinau G, Biebermann H, Ruzsa B, Gelmini G, Rideg O, Miseta A, Kovacs GL, Patocs A, Felszeghy E, Nagy EV, Mezosi E, Persani L 2015 Loss-of-function variants in a Hungarian cohort reveal structural insights on TSH receptor maturation and signaling. J Clin Endocrinol Metab 100:E1039-1045.

25. Kopp P 2001 The TSH receptor and its role in thyroid disease. Cell Mol Life Sci 58:1301-1322.

26. Davies TF, Ando T, Lin RY, Tomer Y, Latif R 2005 Thyrotropin receptor-associated diseases: from adenomata to Graves disease. J Clin Invest 115:1972-1983.

27. Rovati GE, Capra V, Neubig RR 2007 The highly conserved DRY motif of class A G protein-coupled receptors: beyond the ground state. Mol Pharmacol 71:959-964.

28. Tsunekawa $\mathrm{K}$, Onigata $\mathrm{K}$, Morimura $\mathrm{T}$, Kasahara $\mathrm{T}$, Nishiyama S, Kamoda T, Mori M, Morikawa A, Murakami M 2006 Identification and functional analysis of novel inactivating thyrotropin receptor mutations in patients with thyrotropin resistance. Thyroid 16:471-479.

29. Beck-Peccoz P, Persani L, Calebiro D, Bonomi M, Mannavola D, Campi I 2006 Syndromes of hormone resistance in the hypothalamic-pituitary-thyroid axis. Best Pract Res Clin Endocrinol Metab 20:529-546.

30. Muzza M, Rabbiosi S, Vigone MC, Zamproni I, Cirello V, Maffini MA, Maruca K, Schoenmakers N, Beccaria L, Gallo F, Park SM, Beck-Peccoz P, Persani L, Weber G, Fugazzola L 2014 The clinical and molecular characterization of patients with dyshormonogenic congenital hypothyroidism reveals specific diagnostic clues for DUOX2 defects. J Clin Endocrinol Metab 99:E544-553.

31. Pera A, Dossena S, Rodighiero S, Gandia M, Botta G, Meyer G, Moreno F, Nofziger C, Hernandez-Chico C, Paulmichl M 2008 Functional assessment of allelic variants in the SLC26A4 gene involved in Pendred syndrome and nonsyndromic EVA. Proc Natl Acad Sci U S A 105:18608-18613.

32. Pfarr N, Borck G, Turk A, Napiontek U, Keilmann A, Muller-Forell W, Kopp P, Pohlenz J 2006 Goitrous congenital hypothyroidism and hearing impairment associated with mutations in the TPO and SLC26A4/PDS genes. J Clin Endocrinol Metab 91:2678-2681.

33. Park HJ, Shaukat S, Liu XZ, Hahn SH, Naz S, Ghosh M, Kim HN, Moon SK, Abe S, Tukamoto K, Riazuddin S, Kabra M, Erdenetungalag R, Radnaabazar J, Khan S, Pandya A, Usami SI, Nance WE, Wilcox ER, Riazuddin S, Griffith AJ 2003 Origins and frequencies of SLC26A4 (PDS) mutations in east and south Asians: global implications for the epidemiology of deafness. J Med Genet 40:242-248.

34. Nagashima T, Murakami M, Onigata K, Morimura T, Nagashima K, Mori M, Morikawa A 2001 Novel inactivating missense mutations in the thyrotropin receptor gene in Japanese children with resistance to thyrotropin. Thyroid 11:551-559.

Address correspondence to: Jukka Kero, $M D, P h D$

Department of Physiology Institute of Biomedicine University of Turku Kiinamyllynkatu 10 20520 Turku Finland

E-mail: jukka.kero@utu.fi 